\title{
Apropriação da Matemática Moderna no Curso Normal do Instituto Estadual de Educação Assis Brasil: análises de diários de classe de 1970
}

\author{
De las matemáticas modernas en el curso normal del Instituto Estadual de \\ Educação Assis Brasil: análisis de diarios de clase de 1970 \\ Appropriation of Modern Mathematics in the Normal Course of the \\ Instituto Estadual de Educação Assis Brasil: analyzes of class diaries of \\ 1970
}

\author{
Makele Verônica Heidt ${ }^{1}$
}

\begin{abstract}
Resumo
O presente artigo tem como propósito analis ar como ocorreu a apropriação da Matemática Moderna no Instituto Estadual de Educação Assis Brasil (IEEAB), no ano de 1970. A instituição de ensino mencionada se destaca por ter sido a primeira escola a oferecer curso de formação de professores para os anos iniciais, em Pelotas, no final da década de 1920. Para realizar a análise foram investigados diários de classe de sete professores da área de matemática do IEEAB. Usa como caminho investigativo a pesquisa documental num diálogo com a História Cultural, sendo Michel de Certeau o principal teórico escolhido. Por meio das primeiras análises, foi constatada a presença da Matemática Moderna nas salas de aula do IEEAB, abordando conteúdos característicos da Matemática Moderna, como a teoria dos conjuntos, funções, bases numéricas, plano cartesiano, sentenças lógicas, números cardinais, relações e a forte presença da simbologia matemática. Foi dado ênfase a metodologia sugerida por educadores apoiadores do movimento, como Zoltan Dienes e Jean Piaget. Houve uma resistência por parte de alguns professores em trabalhar com a nova proposta curricular, esses continuaram a usar a matemática tradicional em suas aulas. E também, foi identificado um personagem que esteve à frente da divulgação das ideias da Matemática Moderna em Pelotas e no Rio Grande do Sul.
\end{abstract}

Palavras-Chave: Matemática Moderna; formação de professores; curso normal; normalistas.

\section{Resumen}

El presente artículo tiene como propósito analizar cómo ocurrió la apropiación de la Matemática Moderna en el Instituto Estatal de Educación Assis Brasil (IEEAB), en el año 1970. La institución de enseñanza mencionada se destaca por haber sido la primera escuela a ofrecer curso de formación de profesores para los años iniciales, en Pelotas, a finales de la década de 1920. Para realizar el análisis fueron investigados diarios de clase de siete profesores del área de matemáticas del IEEAB. Utiliza como camino investigativo la investigación documental en un diálogo con la Historia Cultural, siendo Michel de Certeau el principal teórico escogido. Por medio de los primeros análisis, se constató la presencia de la Matemática Moderna en las aulas del IEEAB, abordando contenidos característicos de la Matemática Moderna, como la teoría de los conjuntos, funciones, bases numéricas, plano cartesiano, sentencias lógicas, números cardinales, relaciones y la una fuerte presencia de la simbología matemática. Se dio énfasis a la metodología sugerida por educadores apoyadores del movimiento, como Zoltan Dienes y Jean Piaget. Hubo una resistencia por parte de algunos profesores en trabajar con la nueva propuesta curricular, estos continuaron usando las matemáticas tradicionales en sus clases. Y también, fue identificado un personaje que estuvo al frente de la divulgación de las ideas de la Matemática Moderna en Pelotas y en Rio Grande do Sul.

Palabras claves: Matemáticas Modernas; formación de profesores; curso normal; normalistas.

\footnotetext{
${ }^{1}$ Mestranda em Educação Matemática, UFPEL; Pelotas; Brasil; RS; makele_heidt@hotmail.com
} 


\begin{abstract}
The purpose of this article is to analyze how the appropriation of Modern Mathematics occurred in the Instituto Estadual de Educação Assis Brasil (IEEAB) in 1970. The above-mentioned teaching institution stands out because it was the first school to offer teacher training courses for the initial years, in Pelotas, at the end of the 1920s. In order to perform the analysis, class diaries of seven IEEAB mathematics teachers were investigated. It uses as research path documentary research in a dialogue with Cultural History, with Michel de Certeau being the main theoretician chosen. Through the first analyzes, the presence of Modern Mathematics in the IEEAB class rooms was observed, addressing characteristic contents of Modern Mathematics, such as the theory of sets, functions, numerical bases, Cartesian plane, logical sentences, cardinal numbers, relations and strong presence of mathematical symbology. Emphasis was placed on the methodology suggested by educators supporting the movement, such as Zoltan Dienes and Jean Piaget. There was resistance on the part of some teachers to work with the new curriculum proposal, they continued to use traditional mathematics in their classes. Also, a character was identified who was at the forefront of the dissemination of the ideas of Modern Mathematics in Pelotas and Rio Grande do Sul.
\end{abstract}

Keywords: Modern Mathematics; teacher training; normal course; normalists.

\title{
1. Introdução
}

O presente artigo tem o propósito de investigar como a Matemática Moderna foi apropriada no curso Normal do Instituto Estadual de Educação Assis Brasil (IEEAB), no início da década de 1970. A instituição de ensino referida foi a primeira escola do município de Pelotas a oferecer o curso de formação de professores para os anos iniciais. Para cumprir com esta proposta foram analisados diários de classe do IEEAB, encontrados no acervo da instituição, referentes ao ano de 1970, período em que o Movimento da Matemática Moderna estava em seu auge no Brasil.

Segundo a concepção de Roger Chartier a apropriação "tem por objectivo uma história social das interpretações, remetidas para as suas determinações fundamentais (que são sociais, institucionais, culturais) e inscritas nas práticas específicas que as produzem” (2002, p. 26). Neste estudo é enfocada a história social das interpretações referentes à Matemática Moderna e sua inserção no IEEAB, buscando vestígios do que chegou nas salas de aula, quais professores foram os mediadores, como e porque eles incorporaram esse movimento. Ressaltando que a Matemática Moderna não foi apropriada de forma homogênea nas diferentes regiões do país.

Adquirir tal conhecimento sobre as mudanças que foram ocorrendo no currículo de matemática proporciona resultados na postura do profissional em sala de aula. Segundo Valente (2010), os professores de matemática que não tem conhecimento sobre a História da Educação Matemática, com frequência, acabam levantando afirmações extremamente pessimistas sobre o ensino atual, como, declarar que "o ensino de hoje caiu de nível" ou que "os alunos eram mais inteligentes em outros tempos", sentenças essas firmadas apenas no 
senso comum. A História da Educação se compromete a problematizar essas afirmações que possuem fundo ficcional, memorialístico e a-histórico. Busca desconstruir essas representações do passado, apresentando aquelas firmadas na crítica aos documentos e fontes das práticas pedagógicas realizadas em outros tempos.

Assim, com o estudo da História da Educação Matemática, os professores evitam cometer esses anacronismos recorrentes citados anteriormente e passam a conhecer quais foram as mudanças que ocorreram no ensino e na aprendizagem da matemática, bem como os seus motivos. E tal conhecimento possibilita realizar reflexões e buscar melhorias para o ensino atual.

As análises dos documentos investigados dialogam com Michel de Certeau (1982). Segundo ele, o historiador precisa ser cuidadoso no trabalho da constituição e da interpretação de documentos, pois a história não é uma crítica epistemológica, aquilo que aparenta ser uma verdade é ainda apenas um prenúncio. Toda interpretação histórica necessita de um sistema de referência, dado que as práticas mudam seus significados e sentidos no curso de diferentes períodos históricos.

Por meio dos registros nos diários de classe almeja-se verificar quais e de que modo os conteúdos da Matemática Moderna estavam sendo contemplados na formação das normalistas do IEEAB e buscar indícios de como essa proposta de reforma curricular chegou nas salas de aula e por meio de quem.

\section{Movimento da Matemática Moderna}

Segundo Guimarães (2007), ao final da II Guerra Mundial, a ideia de que se necessitava com urgência de uma reforma no ensino de Matemática, começou a tomar forma em diferentes países europeus e também nos Estados Unidos.

A partir do final da década de 1950, professores de matemática, pedagogos e outros sujeitos envolvidos com a educação no Brasil e no mundo, se ocuparam em debates sobre o requerimento da renovação do ensino da Matemática, nos diferentes níveis de ensino (ALVES, 2013).

A Matemática Moderna foi uma proposta de renovação do currículo de Matemática, entendida como melhoria do ensino, elaborada em países desenvolvidos e posteriormente adotada no Brasil. A proposta desencadeou o movimento conhecido como Movimento da Matemática Moderna (BÚRIGO, 1989).

Segundo a maioria dos pesquisadores foi os Estados Unidos o responsável de disseminar o Movimento da Matemática Moderna (MMM) como reforma para o mundo, 
através de eventos, grupos de estudos, e outros meios (ALVES, 2013). E foram as iniciativas desenvolvidas no país que tiveram a maior influência na introdução do movimento no Brasil (BÚRIGO, 1989).

O enfoque da estrutura do ensino de matemática no MMM é resultado dos estudos da psicologia, representados por Piaget, e das pesquisas de Nicolas Bourbaki. Piaget defende que a metodologia para o ensino da matemática precisava abordar o desenvolvimento das estruturas mentais, que não são intuitivas, e não se constitui pela imposição de modelos matemáticos, mas desenvolvido por atividades diversas (ALVES; SILVEIRA, 2016).

O ideário do MMM tinha a intenção de concentrar o ensino da matemática através da teoria dos conjuntos e estruturas algébricas, de modo que conseguisse renovar seu ensino, sem abrir mão, totalmente, do que se ensinava na escola.

Os principais conteúdos a serem trazidos para a escola foram a própria teoria dos conjuntos, os conceitos e fundamentos de grupo, anel e corpo, espaços vetoriais, cálculo diferencial e integral, matrizes, álgebra de Boole e bases de sistemas de números (PEREIRA, p. 72,2010$)$.

Em sua idealização, o MMM planejava profundas mudanças nas perspectivas metodológicas do ensino de matemática, adição de novos conteúdos para os diferentes níveis de ensino e o estabelecimento de uma nova postura diante da matemática e seu ensino escolar (PEREIRA, 2010).

O modo de implementar o MMM no Brasil ocorreu de diversas formas e constata que chegou ao Brasil por intermédio da participação de professores brasileiros em congressos internacionais. Esses professores traziam para o país as ideias que eram discutidas e os demais professores foram aderindo por acharem necessária a reforma (ALVES; SILVEIRA, 2016).

O movimento teve seu auge no Brasil no período de 1961 a 1979, esse intervalo pode ser caracterizado por várias ações em prol da circulação da Matemática Moderna entre os professores, em diversas localidades. Essas ações se evidenciam pela oferta de cursos, encontros, congressos, simpósios e seminários referentes à Matemática Moderna (BORGES, 2011).

O engajamento dos professores decorria não só do fato de que era a única proposta mais elaborada a que tinham acesso, mas do convencimento deles em relação à proposta, da aceitação da proposta como adequada às necessidades do ensino de Matemática no Brasil.

No início dos anos 60, as ideias do MMM foram inseridas e fortalecidas no Brasil por meio da criação do Grupo de Estudos sobre o Ensino da Matemática (GEEM), em São Paulo; o Núcleo de Estudos e Difusão do Ensino da Matemática (NEDEM), criado no estado do 
Paraná, em 1962; e a criação do Grupo de Estudos sobre o Ensino da Matemática de Porto Alegre (GEEMPA), no Rio Grande do Sul, em 1970 (BÚRIGO, 1989).

Ainda segundo Búrigo (1989), no final de 1963, o MMM em São Paulo já havia se constituído no desaguadouro dos esforços de valorização e renovação do ensino da matemática no secundário. Havia conquistado um amplo espaço de divulgação na imprensa, multiplicava e sistematizava suas atividades e aplicava sua esfera de ação, atraindo novos participantes.

Os efeitos desse movimento são percebidos no ensino de Matemática atual, sinalizando para novas formas de raciocínio lógico-matemático e com a introdução da teoria dos conjuntos no currículo de Matemática.

\title{
3. O acervo documental do Instituto Estadual de Educação Assis Brasil
}

A instituição escolhida para a pesquisa foi o IEEAB, uma escola pública, situada na região central do município de Pelotas. Foi fundada em 13 de fevereiro de 1929 e se destaca por ter sido a primeira instituição do município a oferecer curso de formação para professores do ensino primário. (AMARAL; AMARAL, 2007).

$\mathrm{O}$ acervo do IEEAB se encontra em uma sala anexa ao pátio da escola e o mesmo se mantém fechado em tempo integral, sendo aberto apenas para o depósito de documentos. $\mathrm{O}$ material em seu interior não está higienizado, e o espaço dispõe de precária situação de preservação dos documento, pois sofre com infiltração de luz solar e, em dias de chuva, de água. E ainda, como os documentos não tiveram os devidos cuidados de acondicionamento e armazenamento, estão vulneráveis a agentes biológicos, como traças, fungos e cupins e agentes poluentes, como poeira, fuligem e ácidos, que são os principais fatores de deterioração de acervos (TEIXEIRA, 2014).

É válido ressaltar que essa é a situação mais recorrente em que os acervos escolares são encontrados, como relata Souza:

\begin{abstract}
Amontoados em porões, debaixo de escadas, em salas apertadas, distribuídos ao acaso em armários e caixas, descuidados e sem interesse, documentos, quase sempre administrativos, além de coleções de instrumentos científicos, livros didáticos, móveis antigos, troféus, medalhas, entre outros objetos, sobrevivem a intempéries, goteiras, condições de insalubridade, falta de identificação, organização e armazenamento adequado na maioria das escolas (SOUZA apud RIOS, 2015, p. 11).
\end{abstract}

Souza descreve uma realidade comum de encontrar ao adentrar em acervos escolares. A maioria das escolas já descartou os documentos ou os mantêm sem os devidos cuidados de acondicionamento necessário para a preservação. Nem sempre essa situação é descuido das 
instituições, por mais que tenham um desejo de ter o arquivo documental organizado e disponível, não possuem o financiamento por meio do governo.

Para realizar a coleta de dados no acervo do IEEAB, foi preciso fazer uso dos equipamentos de proteção individual, ou seja, estar vestindo jaleco, luvas, touca e máscara, devida a não higienização dos documentos.

Com as devidas medidas de proteção, foi necessário escolher os documentos escolares com maior potencial para representar as aulas lecionadas no ano de 1970. Entre os documentos encontrados estavam fichas de ex-professores e ex-alunos, atas, fotografias, jornais, livros didáticos mais recentes, dentre outros, os documentos que mais se adequaram ao propósito desta pesquisa foram os diários de classe do curso Normal. Os diários de classe contêm a lista de frequência dos alunos e o registro dos conteúdos que foram trabalhados em aula a cada dia.

Segundo Certeau, "a história oscila, então, entre dois pólos. Por um lado remete a uma prática, logo, a uma realidade, por outro é um discurso fechado, o texto que organiza e encerra um modo de inteligibilidade" (1982, p. 25). Assim, em sequência, será discorrido sobre o conteúdo dos diários encontrados.

\subsection{Diários de Classe de 1970}

Foram encontrados diários de classe de sete professores que lecionaram disciplinas voltadas à área da Matemática, foram os professores Cecy Sacco e Felicidade Valli, da disciplina de Matemática, Gilca da Silva, Edi Pradier, Eoni Xavier e Heloisa Merchereffe, de Didática da Matemática e o professor Osvaldo Pinho que lecionava Estatística. Dentre esses professores, verificando o material, foi constatado que apenas três professoras levaram para a sala de aula conteúdos referentes a Matemática Moderna no ano de 1970, as professoras Cecy Sacco, Eoni Xavier e Felicidade Valli.

O curso Normal acontecia com disciplinas semestrais, a professora Eoni Xavier lecionou Didática da Matemática para a $4^{\mathrm{a}}$ série no segundo semestre do ano. Os conteúdos de Matemática Moderna trabalhados foram noções de teoria dos conjuntos, correspondência biunívoca e plano cartesiano, porém ainda não foram muito presentes durante $\mathrm{o}$ ano, ocuparam o equivalente a um mês das aulas.

A teoria dos conjuntos é apontada por muitos professores, pais e alunos, como a principal mudança em relação ao currículo anterior da matemática. Foi inserida no currículo 
de matemática com o intuito de auxiliar na compreensão dos conceitos aritméticos de números e operações.

As aulas de matemática ministradas pela professora Felicidade Valli contemplaram duas turmas de $2^{\mathrm{a}}$ série e uma de $3^{\mathrm{a}}$ série. $\mathrm{Na} 2^{\mathrm{a}}$ série a professora abordou os conteúdos Teoria dos Conjuntos, relações, funções e números cardinais, que dizem respeito a Matemática Moderna, tais conteúdos foram trabalhados vez e outra durante os semestres, mesclando com a matemática "tradicional".

Com a $3^{\mathrm{a}}$ série único registro que mostra atividade envolvendo a Matemática Moderna, foi quando trabalhou máximo divisor comum e mínimo múltiplo comum pelas operações de conjuntos, em apenas uma aula durante o semestre.

Entre as três professoras, quem mais levou a Matemática à sala de aula foi a professora Cecy Sacco. Suas aulas foram direcionadas para quatro turmas de $1^{\text {a }}$ série e duas de $2^{\mathrm{a}}$ série. Ao olhar para os registros das turmas de $1^{\mathrm{a}}$ série é possível constatar que a Matemática Moderna contemplou integralmente as aulas da professora Cecy Sacco, no ano de 1970, presente na teoria dos conjuntos, ao trabalhar, por exemplo, com os conjuntos unitário, binário e vazio, partes de um conjunto, diagramas, etc. Como também, ao aplicar o produto cartesiano, sentenças lógicas, relações e funções, com as turmas. E ainda, os registros mostram a forte presença da simbologia moderna da teoria dos conjuntos.

Cabe destacar que no primeiro semestre a professora recomendou a leitura das biografias de Leonhard Euler (1707-1783) e Georg Cantor (1845-1918). Ela estimulou tal leitura visando o conhecimento sobre esses personagens e de suas contribuições para a matemática. Euler foi matemático destacado do século XVIII e trabalhou com diagramas, por sua vez Cantor viveu no século XIX e é conhecido como pai da teoria dos conjuntos.

Cecy Sacco registra que utilizou em sala de aula o "material do Dienes". Zoltan Dienes (1918-2014) foi um professor de matemática húngaro, que trouxe novas propostas à metodologia da matemática com a introdução dos materiais manipuláveis, como os blocos lógicos, material multibase e o material dourado, para a realização de atividades, que, em sua maioria, eram desenvolvidas em grupo (MEDINA, 2016).

Segundo Búrigo (1989), as ideias de Dienes, em especial com os blocos lógicos, começaram a ser difundidas no Brasil em 1970. O professor também esteve no Brasil divulgando sua teoria. Sua primeira vinda foi em 1971, a convite do GEEM (Grupo de Estudos do Ensino da Matemática). Destaque em especial, a presença de Dienes na I e II Jornada de Estudos sobre a Aprendizagem da Matemática, que aconteceram em Porto Alegre, 
nos anos 1972 e 1973. A vinda de Dienes à capital do Rio Grande do Sul, se deu por solicitação do GEEMPA (Grupo de Estudos sobre o Ensino de Matemática de Porto Alegre).

Os registros indicam que Sacco foi influenciada pelas ideias de Dienes ao utilizar os blocos lógicos com recorrência durante o ano. Levando em consideração que as propostas pedagógicas de Dienes começaram a ser introduzidas no Brasil em 1970, nota-se que Cecy Sacco estava inteirada nas inovações de ensino da matemática e dedicada em aplicá-las com suas alunas.

Evidenciam ainda, a importância concedida a abordagem intuitiva, que Cecy Sacco demonstra nas aulas em que utilizou o estudo dirigido como metodologia, reconhecendo o papel das alunas no processo ensino e aprendizagem, colocando-as como protagonistas do seus próprios conhecimentos. Como reforça Guimarães, a "importância reconhecida ao papel do aluno, nomeadamente, pelo valor atribuído à aprendizagem por descoberta" (GUIMARÃES, 2007, p. 43).

Nota-se que a professora acentuou e trabalhou intensivamente com os diagramas e gráficos, tanto de maneira teórica, quanto na prática, conforme indicam aulas no mês de agosto em que o pátio da escola foi usado para a ilustração dos diagramas, assim como os blocos lógicos. Fazendo alusão a ideia que o aluno deve experienciar, defendida por Jean Piaget, personagem que teve forte influência nos princípios do Movimento da Matemática Moderna, no que diz respeito ao campo da psicologia. Segundo Piaget:

O recurso à experiência e à ação, e de modo geral à pedagogia dita ativa, entre os procedimentos de iniciação matemática, não comprometem em nada o rigor dedutivo posterior do pensamento matemático, bem ao contrário: o preparam, fornecendo-lhe bases reais e não simplesmente verbais (PIAGET apud VALENTE, 2008, p. 585).

Com as turmas de $2^{\mathrm{a}}$ série a professora ainda trabalhou bases de numeração e utilizou a nomenclatura "números cardinais", que são traços da Matemática Moderna. As observações feitas para as aulas da $1^{\mathrm{a}}$ série, quanto ao uso dos blocos lógicos e a opção de trabalhar com o estudo dirigido, recaem sobre as aulas da $2^{\mathrm{a}}$ serie também. Apesar de presente, nas turmas de $2^{\mathrm{a}}$ série a Matemática Moderna foi bem menos presente, predominando a matemática "tradicional".

A professora Cecy Sacco foi a que mais aderiu ao MMM entre os professores de matemática do IEEAB, no acervo da escola foi encontrado o registro de dispensa de uma aula sua para participar de uma palestra sobre Matemática Moderna administrada pela professora Joana Brender, ainda no ano de 1965. A ministrante foi uma das divulgadoras das ideias da Matemática Moderna a nível estadual. 


\section{Conclusões}

Ao olhar para os diários de classe de 1970 encontrados no acervo do IEEAB foi possível identificar a resistências da maioria dos professores de matemática do curso Normal em aderir as propostas da Matemática Moderna, mesmo quando o movimento estava em seu auge no país.

Em contra partida uma das professoras se mostrou engajada a trabalhar com o conteúdo em sala de aula, foi atrás de palestras e trouxe materiais novos para aplicar com suas alunas. Segundo Certeau, "desde que se procure o 'sentido histórico' de uma ideologia ou de um acontecimento, encontram-se não apenas métodos, idéias ou uma maneira de compreender, mas a sociedade à qual se refere a definição daquilo que tem "sentido"” (1982, p. 39). Assim, a apropriação da Matemática Moderna no IEEAB teve oscilações de acordo com a motivação de cada professor, enquanto alguns não inseriram a Matemática Moderna em suas aulas, outros trabalharam de forma moderada e ainda, uma professora utilizou-se dos conteúdos o semestre inteiro.

Ao aderir as ideias de Dienes e de Piaget, revela que a Matemática Moderna que chegou ao IEEAB era voltada para a metodologia e não apenas focada nos conteúdos e simbologia. E ainda, foi encontrado o nome de um personagem que fez a divulgação das ideias do movimento para professores do IEEAB, a professora Joana Brender.

\section{Referências}

ALVES, A. M. M. A Matemática Moderna no ensino primário gaúcho (1960-1978): uma análise das coleções de livros didáticos Estrada Iluminada e Nossa Terra Nossa Gente. 2013. 320f. Tese (Doutorado em Educação) - Instituição de Ensino, Universidade Federal de Pelotas, Capão do Leão. 2013.

ALVES, A. M. M.; SILVEIRA, D. N. Uma Leitura sobre as Origens do Movimento da Matemática Moderna (MMM) no Brasil. Tópicos Educacionais, Recife, n. 2, p. 6-22, jul./dez. 2016. ISSN 2448-0215. Disponível em: https://periodicos.ufpe.br/revistas/topicoseducacionais/article/viewFile/22667/18731. Acesso em: 15 jan. 2019.

AMARAL, G. L.; AMARAL, G. L. Instituto de Educação Assis Brasil: entre a memória e a história 1929-2006. Pelotas: Seiva, 2007. 183 p.

BORGES, R. A. S. Circulação e apropriação do ideário do Movimento da Matemática Moderna nas séries iniciais: as revistas pedagógicas no Brasil e em Portugal. 2011. 295f. Tese (Doutorado em Educação Matemática) - Instituição de Ensino: Universidade Anhanguera de São Paulo, São Paulo. 2011. 
BÚRIGO, E. Z. Movimento da Matemática Moderna no Brasil: estudo da ação e do pensamento de educadores matemáticos nos anos 60. 1989. 292 f. Dissertação (Mestrado em Educação) - Instituição de Ensino: Universidade Federal do Rio Grande do Sul, Porto Alegre, 1989.

CHARTIER, R. (2002). A História Cultural: entre práticas e representações. Trad. Sob a direção de Maria Manuela Galhardo. Algés, Portugal: DIFEL, 2002.

DE CERTEAU, M. (1982). A escrita da história. Trad. Sob a direção de Maria de Lourdes Menezes. Rio de Janeiro: Forense, 1982.

GUIMARÃES, H. M. Por uma Matemática Nova nas Escolas Secundárias: perspectivas e orientações curriculares da Matemática Moderna. In: MATOS, J. M.; VALENTE, W. R. (Org.). A Matemática Moderna nas escolas do Brasil e de Portugal: primeiros estudos, São Paulo: Editora Da Vinci, 2007. p. 21-45.

MEDINA, D. Como ensinar matemática nos primeiros anos escolares em tempos do Movimento da Matemática Moderna? Revista Diálogo Educacional, Curitiba - PR, v. 16, n. 48, p. 403-422, maio/ago. 2016. ISSN 1518-3483. Disponível em: https://periodicos.pucpr.br/index.php/dialogoeducacional/article/view/2056/1960. Acesso em: 15 jan. 2019.

PEREIRA, L. H. F. Os discursos sobre matemática publicados na Revista do Ensino/RS (1951 - 1978). 2010. 315f. Tese (Doutorado em Educação) - Instituição de Ensino: Pontifícia Universidade Católica do Rio Grande do Sul, Porto Alegre. 2010.

RIOS, D. F. Educação Matemática no Rio Grande do Sul: instituições, personagens e práticas entre 1890 e 1970. Projeto de Pesquisa. Universidade Federal de Pelotas. Pelotas, 2015. $12 \mathrm{f}$.

TEIXEIRA, V. B. Os Desafios da Preservação: a importância dos procedimentos de conservação preventiva para a salvaguarda de acervos. In: AMARAL, G. L. (Org.). Museu do Colégio Municipal Pelotense: um espaço para a pesquisa o ensino e a extensão 2004 2014. Pelotas: EDUCAT, 2014. p. 133-144.

VALENTE, W. R. Osvaldo Sangiorgi e o Movimento da Matemática Moderna no Brasil. Revista Diálogo Educacional, Curitiba, v. 8, n. 25, p. 583-613, set./dez. 2008. ISSN 15183483. Disponível em: https://periodicos.pucpr.br/index.php/dialogoeducacionalarticle/view/3724/3640. Acesso em: 15 jan. 2019.

VALENTE, W. R. História da Educação Matemática: considerações sobre suas potencialidades na formação do professor de matemática. Bolema, Rio Claro- SP, v. $23, \mathrm{n}^{\circ}$ 35A, p. 123-136, abril 2010. ISSN 0103-636X. Disponível em: https://repositorio.ufsc.br/xmlui/bitstream/handle/123456789/160381/3735-18103-1PB1.pdf?sequence=1\&isAllowed=y. Acesso em: 15 jan. 2019. 